\title{
A quasi-experimental study to assess the effectiveness of doula care during intra-natal period on level of anxiety among labouring mothers admitted in CLR, Nehru Hospital, PGIMER, Chandigarh
}

\author{
heena kapoor ${ }^{1}$, sunita sharma ${ }^{2}$, Sukhjit Kaur $^{2}$, and Pooja Sikka² \\ ${ }^{1}$ Affiliation not available \\ ${ }^{2}$ Post Graduate Institute of Medical Education and Research
}

September 22, 2020

\begin{abstract}
Introduction: Labour is one of the most exciting and important events of woman's life, but often is accompanied by fear related to childbirth. Objective: To assess the effectiveness of doula care on level of anxiety among labouring mothers. Design: Quasi-experimental Setting: CLR, Nehru Hospital, PGIMER, Chandigarh. Sample: 120 labouring mothers Methods: Tools used for data collection was interview schedule composed of socio-demographic and obstetrical profile and state and trait anxiety inventory used for the assessment of anxiety level. The Level of anxiety was assessed in the experimental group after implementing the doula care (psychological support by doula as a birth companion, effleurage massage, breathing exercises, and positioning) and in the control group after giving routine care. Main outcome: level of anxiety Results: The pre-test showed no difference in anxiety level among both the groups. ( $>>0.05)$. In the post-test there was significantly low anxiety level in experimental group as compared to control group as shown by Mann-Whitney and Wilcoxon Test $(\mathrm{p}<0.05)$. Conclusion It is concluded that doula care is effective in reduction of anxiety during labour. Keywords: Doula, Doula care, Intra-natal period, effleurage massage. Clinical trial registry - India, ctri.nic.in/clinicaltrials/login.php. (CTRI/2019/07/020367)
\end{abstract}

\section{Hosted file}

main document with tables.pdf available at https://authorea.com/users/360901/articles/482445a-quasi-experimental-study-to-assess-the-effectiveness-of-doula-care-during-intranatal-period-on-level-of-anxiety-among-labouring-mothers-admitted-in-clr-nehru-hospitalpgimer-chandigarh

\section{Hosted file}

Figures.pdf available at https://authorea.com/users/360901/articles/482445-a-quasiexperimental-study-to-assess-the-effectiveness-of-doula-care-during-intra-natal-periodon-level-of-anxiety-among-labouring-mothers-admitted-in-clr-nehru-hospital-pgimerchandigarh 